\title{
Utilization of the Transient Liquid Crystal Technique for Film Cooling Effectiveness and Heat Transfer Investigations on a Flat Plate and a Turbine Airfoil
}

\author{
U. Drost, A. Bölcs \\ Swiss Federal Institute of Technology \\ EPFL-LTT \\ Lausanne, Switzerland
}

\author{
A. Hoffs \\ ABB Power Generation Ltd. \\ Gas Turbine Development \\ Baden, Switzerland
}

\begin{abstract}
The transient liquid crystal technique has been used to measure film cooling effectiveness and heat transfer on a flat plate in a free jet, and a turbine airfoil in a linear cascade. A multiple-test regression method has been developed for the data reduction, considering a transient coolant temperature evolution. Flat plate film cooling was investigated for a single row of $35^{\circ}$ inclined holes at Mach numbers of 0.3 and 0.5 , and two turbulence intensities. Downstream of injection heat transfer was increased in-between the holes due to enhanced turbulence caused by the shearing of the coolant and the mainstream. At higher turbulence intensity the range of blowing ratios was broader as lift-off was delayed. Film cooling measurements on the airfoil were conducted at enginerepresentative flow conditions. A maximum effectiveness of 0.3 behind injection was observed on the suction side, with slightly higher values for a double row in comparison to a single row configuration. Due to a high coolant momentum, the effectiveness on the pressure side was very low at about 0.05 for a single row configuration.
\end{abstract}

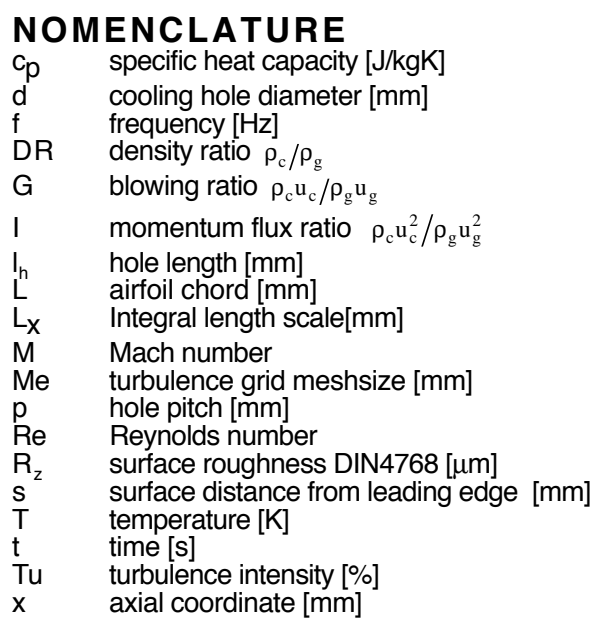

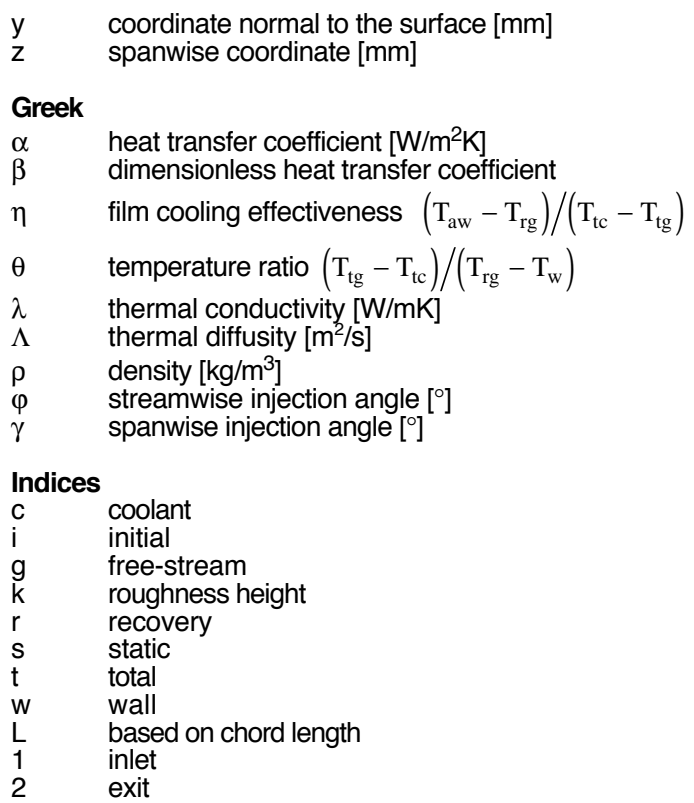

\section{INTRODUCTION}

The power output and efficiency level of a gas turbine improves by increasing the turbine inlet temperature. Since these temperatures exceed the highest allowable blade material temperature the blades have to be cooled to guarantee safe operating conditions. Discrete hole film cooling is an effective way to achieve this objective, provided that the thermal boundary conditions are known accurately. As numerical predictions of three-temperature convection situations on complex geometries as turbine airfoils are not yet sufficiently reliable for design purposes experimental information is urgently needed. Hence, an experimental heat transfer research program has been initiated at the EPFL, and two-temperature situation convection results on flat plate, 
cylinder and airfoil geometries have been recently reported in Häring et al., (1995, 1996) and Hoffs et al. (1995, 1996).

The objective of the present work is to show the utilization of the transient liquid crystal technique in film cooling situations on complex geometries. An evaluation procedure is presented allowing the deduction of both the film cooling effectiveness and heat transfer coefficients from ensembles of 6 to 8 tests conducted at identical aerodynamic, but varying coolant injection temperatures. A similar evaluation procedure has been reported by Wang et al. (1994) being named the temperature matching method. Regression analysis was used to select values of the heat transfer coefficient and adiabatic wall temperature to minimize the sum of squared differences between the measured surface temperature and a semi-infinite transient conduction model. Vedula and Metzger (1991) presented an evaluation procedure based on two distinct measurements where the two unknowns are obtained from a double-equation system. Their measurement setup did not allow true step-changes in the applied fluid temperatures, which was accounted for by using a series of steps for the solution of the semi-infinite model.

In the present paper, a flat plate with a single row of $35^{\circ}$ inclined holes has been investigated for Mach numbers of 0.3 and 0.5, at low and high mainstream turbulence intensities. The blowing ratios were varied between 0.3 and 1.5 at a density ratio of 1.6 , which was obtained with foreign gas injection. A similar film cooling geometry has been used by Ammari et al. (1990), Sinha et al. (1991) and Schmidt et al. (1994), and comparisons are made with results reported by these authors. Ammari et al. showed an increase in heat transfer with respect to an uncooled case for a density ratio of 1.52. Sinha et al. measured film cooling effectiveness at various density ratios, and Schmidt et al. studied the influence of compound angle on effectiveness.

Subsequently, the transient liquid crystal technique was used for effectiveness and heat transfer measurements on a turbine airfoil at engine-representative flow conditions. On the suction side, single and double row injection into an accelerating boundary layer are compared, while pressure side film cooling was only done for one row.

\section{Theory}

The local heat flux in the film cooling situation can be described as follows,

$$
\mathrm{q}=\alpha_{\mathrm{f}}\left(\mathrm{T}_{\mathrm{aw}}-\mathrm{T}_{\mathrm{w}}\right)
$$

where the convection coefficient is based on the unknown adiabatic wall temperature that depends on the supply temperatures of the main and secondary streams and the degree of mixing. In dimensionless form this temperature becomes the film cooling effectiveness, defined for flow with dissipation as (Teekaram et al., 1990),

$$
\eta=\frac{T_{a w}-T_{r g}}{T_{t c}-T_{t g}}
$$

The two unknowns of such a three-temperature situation are thus the heat transfer coefficient $\alpha_{f}$ and the film cooling effectiveness, $\eta$. Both values are functions of the aerodynamic character of the flow field alone (Vedula and Metzger, 1991).
In the present work, these two unknowns are determined by conducting transient tests where the model is suddenly exposed to a steady mainstream. The transient heating of the surface is monitored by the color play of a liquid crystal coating. Initially the model is at a homogenous temperature, so that for short testing times the transient heating near the surface can be described by one-dimensional semi-infinite heat conduction. The governing differential equation and appropriate boundary conditions are then,

$$
\begin{aligned}
& \frac{\partial^{2} \mathrm{~T}}{\partial \mathrm{y}^{2}}=\frac{1}{\Lambda} \frac{\partial \mathrm{T}}{\partial \mathrm{t}} \\
& \lim _{\mathrm{y} \rightarrow \infty} \mathrm{T}(\mathrm{y}, \mathrm{t})=\mathrm{T}_{\mathrm{i}} \\
& \mathrm{T}(\mathrm{y}, 0)=\mathrm{T}_{\mathrm{i}} \\
& -\lambda \frac{\partial \mathrm{T}(0, \mathrm{t})}{\partial \mathrm{y}}=\alpha_{\mathrm{f}}\left(\mathrm{T}_{\mathrm{aw}}-\mathrm{T}(0, \mathrm{t})\right)
\end{aligned}
$$

In the experiments a complication was introduced, since a true step change of the coolant temperature was not possible due to heat exchange in the supply tubing and plenum chamber. Thus, the adiabatic wall temperature became a function of time, which had to be accounted for in the evaluation. The measured coolant temperature distribution was approximated by a power series of the following form,

$$
\mathrm{T}_{\mathrm{tc}}(\mathrm{t})=\sum_{\mathrm{n}=0}^{\mathrm{N}} \mathrm{A}_{\mathrm{n}} \frac{\mathrm{t}^{\mathrm{n}}}{\Gamma(\mathrm{n}+1)}
$$

usually chosen of 4 th to 5 th order (Fig. 1).

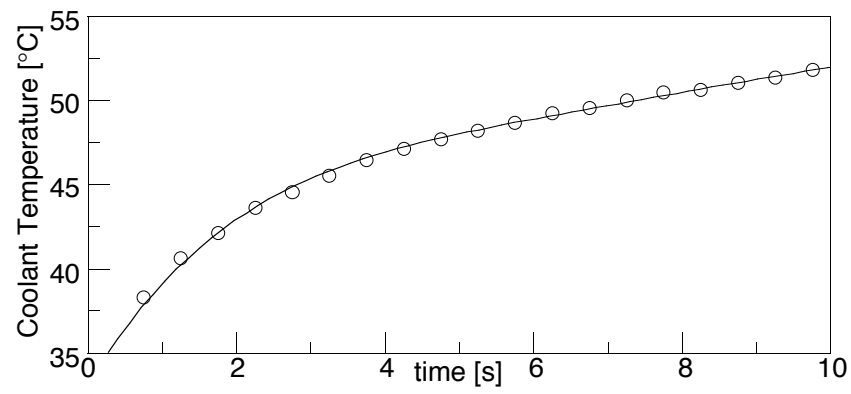

Fig.1 Coolant temperature evolution and 5th order fit

Using this closed expression for $\mathrm{T}_{\text {tc }}$, an analytical solution to the equations ( 3 ) to ( 7 ) was obtained for $y=0$ using the Laplace transform method,

$$
\begin{aligned}
T_{w}-T_{i} & =\left(T_{r g}-\eta T_{t g}-T_{i}\right)\left[1-e^{\beta^{2}} \operatorname{erfc}(\beta)\right] \\
- & \eta \sum_{n=0}^{N}\left\{A_{n}\left(\frac{\kappa}{\alpha_{f}}\right)^{2 n}\left[e^{\beta^{2}} \operatorname{erfc}(\beta)-\sum_{\tau=0}^{2 n}\left([-2 \beta]^{\tau} i^{\tau} \operatorname{erfc}(0)\right)\right]\right\}
\end{aligned}
$$

with 


$$
\begin{aligned}
& \kappa=\frac{\lambda}{\sqrt{\Lambda}}=\sqrt{\rho \cdot \lambda \cdot c_{p}} \\
& \beta=\frac{\alpha_{f} \sqrt{t}}{\kappa}
\end{aligned}
$$

Eq. (8) contains the two unknowns $\alpha_{f}$ and $\eta$, which are deduced via a regression analysis similar to that proposed by Wang et al. (1994). Least squares fitting of the model equation to the wall temperature rise yields the two unknowns. Wang measured the wall temperature during a single experiment with large-band liquid crystals. In theory two points of the temperature history would be sufficient to determine the two unknowns at each point of the surface. However, the measurement uncertainty can be significantly reduced by adding additional points to the evaluation and by applying regression analysis.

In the present work, a single layer of narrow-band liquid crystal was used to avoid additional complications related to the view angle dependency of large-band liquid crystals. Multiple layers of narrow-band liquid crystals could not be employed, because the hue signals recorded by the image processing system did not allow a clear identification of each layer.

According to Vedula and Metzger (1991), several experiments can be evaluated together, if they are conducted under identical aerodynamic conditions but different flow temperatures. Forth et al. (1985) on the other hand mentioned that a constant flow field can only be maintained when both the freestream and injection temperatures are kept constant and only the wall temperature is altered. However, Ligrani and Camci (1985) conducted film cooling tests in compressible, variable property flow, where the coolant temperature variation changed the density ratio. They kept either the blowing ratio, momentum flux ratio or velocity ratio constant and observed alteration in $\eta$ within $+/-10 \%$. The best agreement with constant property measurements was found when the blowing ratio was maintained.

For the present study usually 6 to 8 tests were carried out at identical blowing ratios, total temperatures and liquid crystal temperatures, whereas the coolant injection temperature was varied in a range of $0^{\circ} \mathrm{C}$ to $50^{\circ} \mathrm{C}$. These test ensembles were then evaluated together by fitting eq. (8) through the measured points using a least squares regression procedure. Typical variations of I and DR with $\theta$ for one ensemble are presented in Fig. 2, which shows that the maximum differences are in the order of $8 \%$.

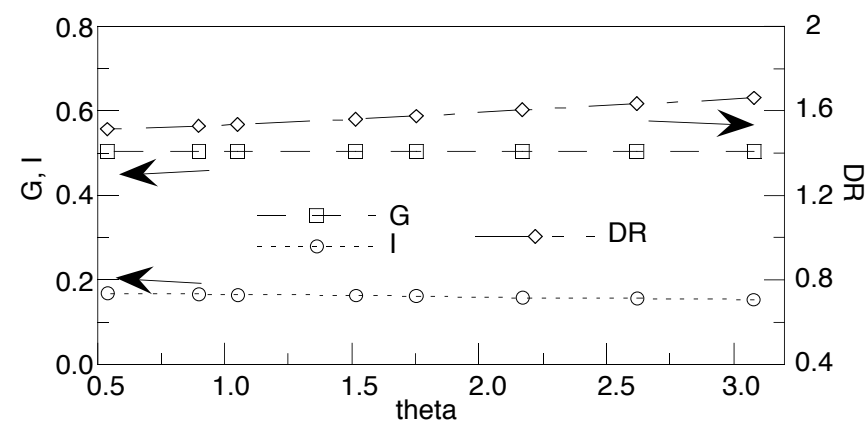

Fig. 2 Variation of G, I, and DR with $\theta$

\section{Measurement uncertainties}

Using only two transient tests for the data evaluation reduces the evaluation analysis to a simple 2 equation problem with 2 unknowns. For such a constellation, typical uncertainties in $\eta$ and $\alpha_{f}$ can be determined according to Kline and McClintock (1953), considering the following major contributors to the uncertainty,

$$
\begin{aligned}
& \mathrm{T}_{\mathrm{w}}=0.3 \mathrm{~K} \\
& \mathrm{~T}_{\mathrm{i}}=0.5 \mathrm{~K} \\
& \mathrm{~T}_{\mathrm{g}}=0.5 \mathrm{~K} \\
& \mathrm{~T}_{\mathrm{c}}=1 \mathrm{~K}
\end{aligned}
$$

$$
\begin{aligned}
& \lambda=3 \% \\
& \Lambda=3 \% \\
& t=2 / 25 s
\end{aligned}
$$

Hence, for two tests uncertainty in heat transfer coefficient yields a value of about $10 \%$, and in local effectiveness a value of $20 \%$ at $\eta=0.1$, decreasing to $6 \%$ for $\eta=0.3$. These values were considered to be too high for systematic film cooling parameter studies and consequently the described multipletest regression procedure was implemented.

For this regression analysis the determination of uncertainty values revealed to be a rather difficult task due to the non-linear character of the regression model. The only direct measure of regression quality is given by the RMS deviations of the actual measured wall temperatures to those obtained from the model, which are of the order of $0.5 \mathrm{~K}$ for gas to initial temperature differences of $30 \mathrm{~K}$. However, this information tells nothing about the uncertainties in $\eta$ and $\alpha_{f}$.

Hence, for the regression method an uncertainty analysis was carried out in two steps. A statistical analysis was conducted by systematically varying the number of tests of an evaluation ensemble. Here, the decrease of average relative deviations in $\eta$ and $\alpha_{f}$ was observed with increasing test numbers. For more than 5 tests, this deviation fell below $1 \%$ so that the ensembles were considered to be in statistical equilibrium (Fig.3).

An uncertainty analysis according to Kline and McClintock (1953) was then carried out using the governing least squares equation derived from eq. (8), considering the contributors given above. Uncertainty in heat transfer coefficient yields a rather constant value of $6 \%$, and in local effectiveness a value of $10 \%$ at $\eta=0.1$, decreasing to $4 \%$ for $\eta=0.3$. For laterally averaged effectiveness, uncertainty yields a value of $8 \%$ for $\eta=0.3$.

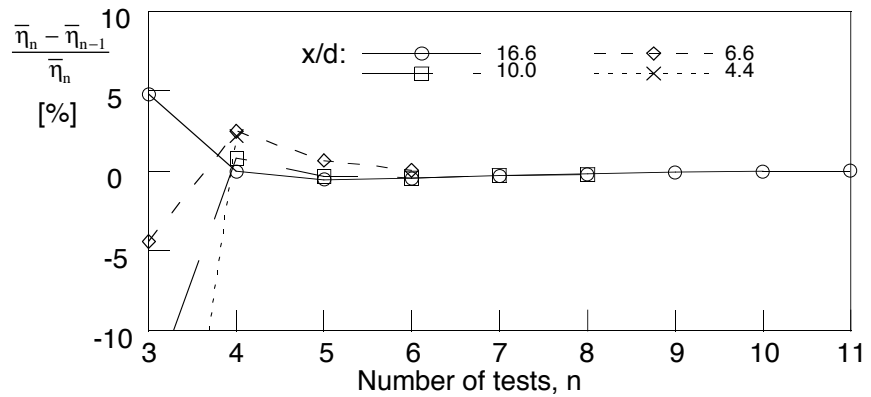

Fig. 3 Average relative error in $\eta$ as a function of test numbers

The effect of the transient coolant temperature distribution (Fig. 1) during the tests with respect to evaluations conducted at constant average coolant temperatures was assessed to 
be up to $8 \%$ for the heat transfer coefficient and up to $16 \%$ for $\eta$.

\section{FLAT PLATE}

\section{Test Facility/Measuring Equipment}

The flat plate measurements were conducted in a free jet test facility with a nozzle diameter of $150 \mathrm{~mm}$ as shown in Fig. 4. The test facility is supplied from a continuously running air source delivering a mass flow up to $10 \mathrm{~kg} / \mathrm{s}$ with a maximum pressure ratio of 3.5 . Total pressure and total temperature were measured in the settling chamber for low turbulence tests. When the turbulence grid was attached to the nozzle, a total pressure probe was used downstream of the screen.

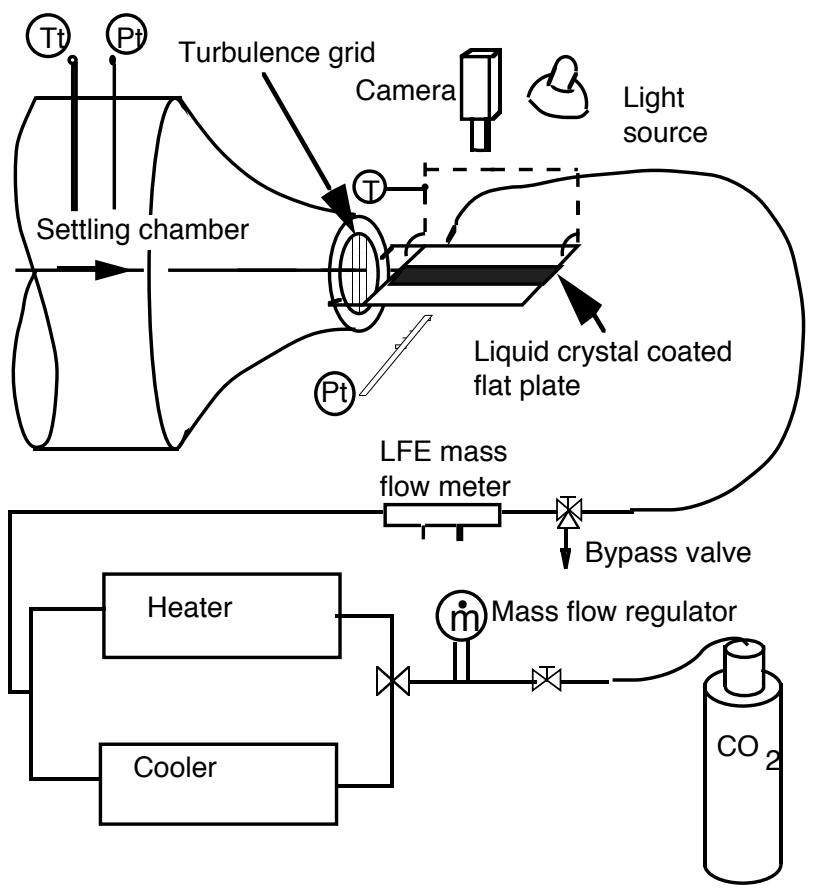

Fig.4 Free jet test facility

The measurements were conducted on a flat plate (Fig. 5 ) made out of perspex. Its leading edge was located 0.35 free-jet diameters downstream of the nozzle and the trailing edge 2.35 diameters. Flowfield surveys showed negligible expansion of the free-jet in this range. The film cooling geometry consisted of one row of 14 holes with diameter $d=1.8$ $\mathrm{mm}$ inclined with $35^{\circ}$ in the flow direction from the surface. The holes were located 36 hole diameters from the leading edge, the lateral spacing of the holes was 3 hole diameters, and the hole length 3.5 hole diameters. The injection system had a feeding chamber in the model itself and supply of the coolant from one side similar to a blade. A special convergent form according to the manifold model of Bajura (1971) was given to the chamber to insure an even coolant distribution to the holes. The cooling holes were sharp entry and the plenum entry section was 60 hole sections. The coolant properties were measured in the plenum chamber by means of two thermocouples and a pressure tapping. Six thermocouples were distributed along the surface to measure the initial temperature of the plate. A strip of $10 \mathrm{~mm}$ large sand paper was pasted onto the leading edge to provoke a laminarturbulent transition at this location, selected according to the critical roughness Reynolds number of $\mathrm{Re}_{\mathrm{k}, \infty}=680$ (Doenhoff and Horton, 1956). The coolant mass flow rate was metered with a Meriam Instr. laminar flow element and additionally with a Brooks Inc. mass flow regulator.

The flat plate was mounted on a turning mechanism which allows its sudden exposure to the main flow in less than $0.1 \mathrm{~s}$. Pivoting the plate activated a bypass valve which fed the coolant into the plate plenum chamber.

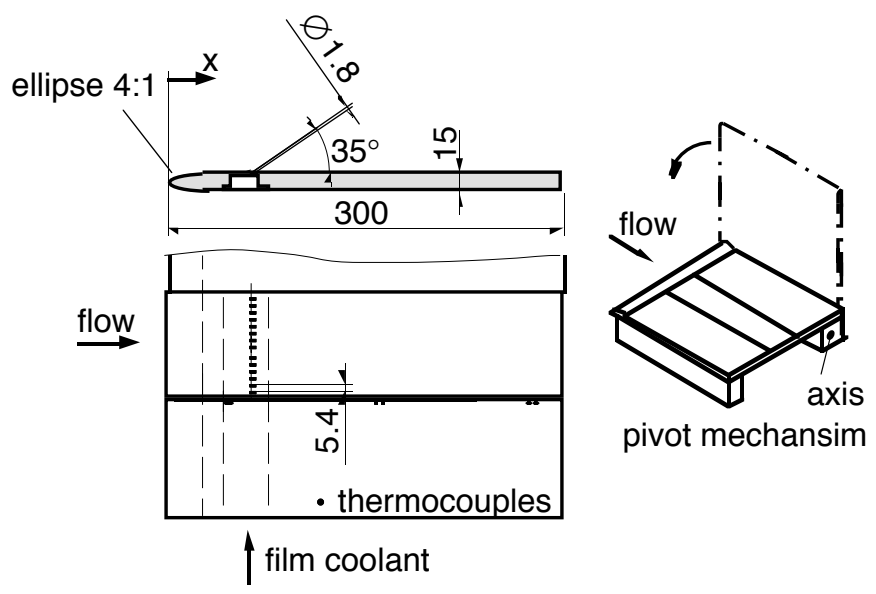

Fig. 5 Flat Plate

Variations in plate Reynolds number were achieved with different inlet flow rates and total pressures whereas the mainstream temperature remained approximately constant at $48^{\circ} \mathrm{C}$. Foreign gas injection using $\mathrm{CO}_{2}$ was employed to achieve a density ratio of 1.6 , as proposed by Teekaram et al. (1989).

\section{Measurement Technique}

The present image processing system is based on the hue capturing technique using an automated image processing system as already described in Häring et al. (1995). Since the color play of the liquid crystals is taken under a certain viewing angle the original surface coordinates are correlated numerically with the camera picture to correct the image distortion.

Narrow-band microencapsulated thermochromic liquid crystals were used for the tests, which were applied to the surface with a precision airbrush, and covered with a thin layer of binder to protect the capsules. Due to the spraying process the surface always exposes a certain roughness so that polishing of the surface with very fine sandpaper became inevitable to obtain smooth and repeatable surface conditions. The surface roughness was measured with a Perthen SP6 profilometer and a piezo-electrique measuring sensor (RFHTB50, 0-50 $\mu \mathrm{m}$ ) on various locations at the plate. For the polished smooth surface an average roughness value of $R_{z}=15 \mu \mathrm{m}\left(R_{a}=1.7 \mu \mathrm{m}\right)$ was found.

\section{TURBULENCE MEASUREMENTS \\ Turbulence Generating Grid}

In order to obtain a high turbulence level, a square array biplane grid constructed with rectangular bars has been inserted. The turbulence grid had a meshsize of $15 \mathrm{~mm}$, a mesh- to barsize ratio of 5 , and was placed 8.5 mesh sizes 
upstream of the injection location to achieve a high turbulence intensity, albeit with a considerable degree of anisotropy.

\section{Turbulence Measurement Data Reduction}

Turbulence intensity decay and length scale growth were measured with a Dantec 55M01 constant temperature anemometer and a standard single hot-wire probe. A high sampling frequency of $40 \mathrm{kHz}$ was chosen to resolve small eddy structures and the sampling time was 5 seconds. The turbulence data was low-pass filtered at $16 \mathrm{kHz}$ to avoid aliasing errors due to contributions from higher frequencies. The probe was calibrated in situ at different mainstream velocities. The calibration curve was then obtained by fitting a fourth order least-squares curve of the density-velocity product as a function of the probe voltage. Fast Fourier transforms were applied to the measured velocity samples and, using the Wiener-Khinchin Theorem (Bendat and Piersol, 1985) the autocorrelation was calculated. Integration of the latter until the first zero-passage led to the integral length scale. The uncertainties for the turbulence level and scale are $0.5 \%$ and $2 \mathrm{~mm}$, respectively.

\section{Turbulence Measurement Results}

Turbulence intensity in the clear free-jet was measured to $1.4 \%$, accompanied by a high integral length scale of $30 \mathrm{~mm}$. The turbulence intensity decay downstream of the grid is shown in Fig. 6 and compares very well to the correlation from Baines and Peterson (1951). At the injection location, the Tu value was $8 \%$ and at the leading edge $15 \%$. Length scale growth was weak yielding a lengthscale of $9 \mathrm{~mm}$ at injection location.

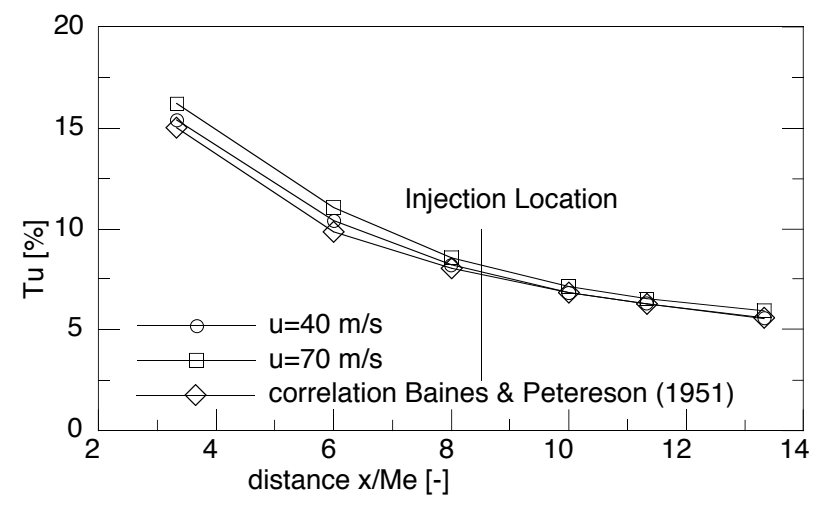

Fig. 6 Turbulence intensity decay downstream of grid

\section{RESULTS AND DISCUSSION FLAT PLATE}

The film cooling measurements on the flat plate had two objectives. First, the relatively straight-forward experimental set-up allowed the preparation and testing of the additional measuring devices. Due to a large number of openly available research work on film-cooled flat plates it was then possible to compare and validate the present measurements.

The range of experimental parameters which were varied in the current study is listed in table 1.

\begin{tabular}{cccccc}
$\mathrm{M}$ & $\mathrm{G}$ & $\mathrm{I}$ & $\mathrm{DR}$ & $\delta_{1} / \mathrm{d}$ & $\mathrm{Tu}[\%]$ \\
\hline 0.3 & 0.3 & 0.06 & 1.6 & 0.127 & 1 \\
0.3 & 0.5 & 0.16 & 1.6 & 0.127 & 1 \\
0.3 & 0.7 & 0.31 & 1.6 & 0.127 & 1 \\
0.3 & 1.0 & 0.63 & 1.6 & 0.127 & 1 \\
0.3 & 1.5 & 1.36 & 1.6 & 0.127 & 1
\end{tabular}

$\begin{array}{llllll}0.3 & 0.3 & 0.06 & 1.6 & 0.127 & \text { high } \\ 0.3 & 0.5 & 0.16 & 1.6 & 0.127 & \text { high } \\ 0.3 & 1.0 & 0.63 & 1.6 & 0.127 & \text { high } \\ 0.3 & 1.5 & 1.36 & 1.6 & 0.127 & \text { high } \\ 0.5 & 0.3 & 0.06 & 1.6 & 0.114 & 1 \\ 0.5 & 0.3 & 0.06 & 1.6 & 0.114 & \text { high } \\ 0.5 & 0.7 & 0.30 & 1.6 & 0.114 & 1 \\ 0.5 & 0.7 & 0.30 & 1.6 & 0.114 & \text { high }\end{array}$

Table 1 Flat plate test conditions

The boundary layer displacement thicknesses given in table 1 were calculated with a correlation from Schlichting (1968) for turbulent boundary layers,

$$
\begin{aligned}
& \delta_{0}=0.37 \frac{\mathrm{x}}{\operatorname{Re}_{\mathrm{x}}^{1 / 5}} \\
& \delta_{1}=\frac{\delta_{0}}{8}
\end{aligned}
$$

\section{FILM COOLING EFFECTIVENESS \\ Effect of blowing/momentum flux ratio}

The complete surface effectiveness distributions were integrated over $27 \mathrm{~mm}$ in the flow center to obtain laterally averaged values $\bar{\eta}$. Fig. 7 shows the evolution of $\bar{\eta}$ for different blowing ratios at a Mach number of 0.3 and $\mathrm{Tu}=1.4 \%$. Some data scatter in the immediate vicinity of injection is due to a lack of optical resolution of the steep temperature gradients in this region. For low blowing ratios $\bar{\eta}$ has a maximum near the holes and monotonically decreases further downstream. Jet lift-off occurs at a blowing rate of about 1 , which flattens the effectiveness in vicinity to the holes, but produces rather high values further downstream. Highest overall effectiveness is observed at $\mathrm{G}=0.7$.

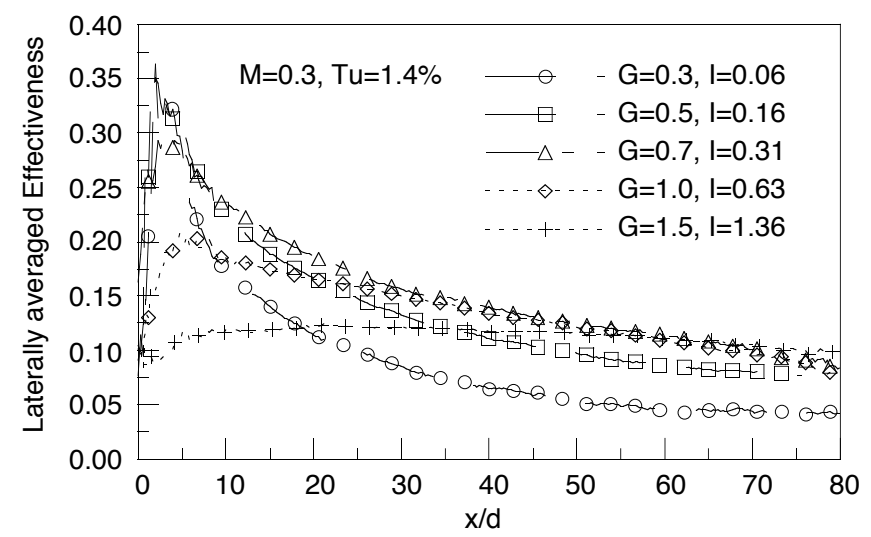

Fig. 7 Laterally averaged effectiveness at various blowing ratios

The excellent resolution of the measurements is illustrated by spanwise effectiveness distributions at different axial positions for $\mathrm{G}=0.5$ shown in Fig. 8. Downstream of the hole centerlines effectiveness values close to unity are obtained at a position of $x / d=3$, whereas in-between the holes no cooling effect is visible. As mixing of the jets occurs through the turbulent boundary layer, the effectiveness peaks gradually level out to a value of 0.2 at $x / d=17$. 


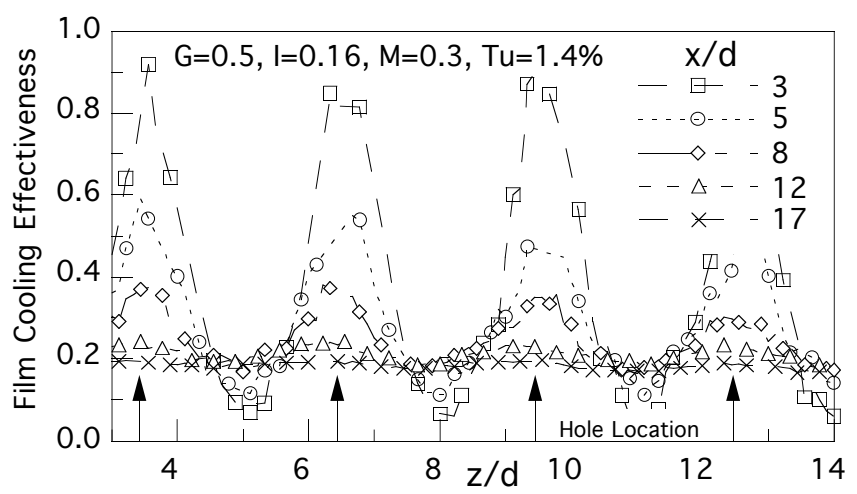

Fig. 8 Spanwise effectiveness distribution

\section{Effect of mainstream turbulence}

The influence of the turbulence intensity on $\bar{\eta}$ is depicted in Fig. 9 for different blowing ratios. For blowing ratios lower than $1, \bar{\eta}$ is lower for the high turbulence cases due to stronger mixing in the boundary layer. However, when the jets start to detach from the surface for a blowing ratio of about 1 , the high turbulence cases perform gradually better, for $\mathrm{G}=1.0$ close to the holes and for $G=1.5$ also further downstream. At high turbulence, a part of the coolant mass flow seems to be shedded from the detaching jets increasing its dispersion into the boundary layer. Schmidt and Bogart (1996) conducted flat plate film cooling measurements at three turbulence intensities $(0.3 \%, 10 \%, 17 \%)$ and observed the same phenomena.

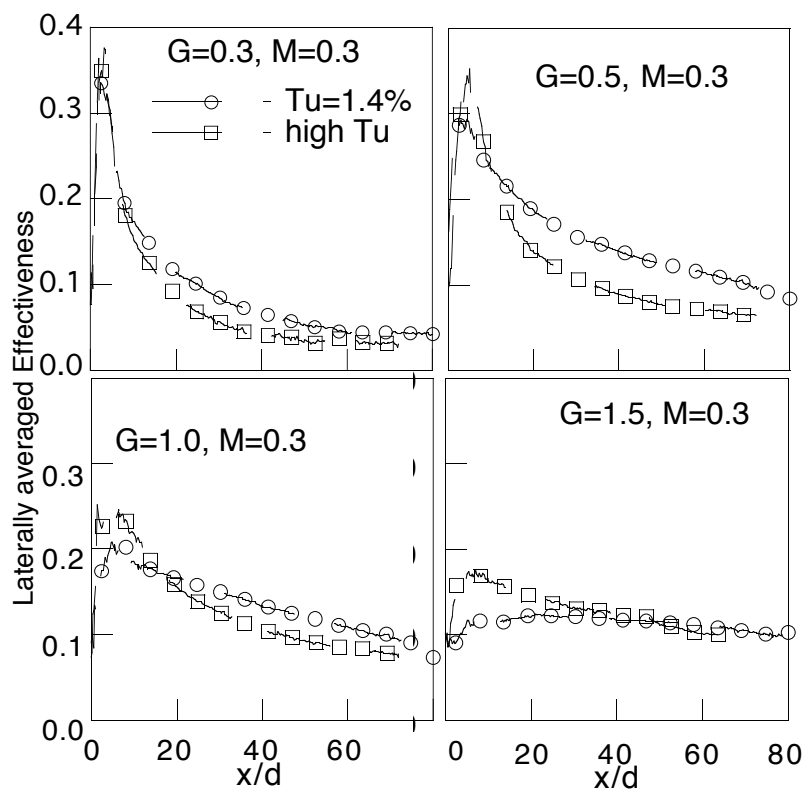

Fig. 9 Laterally averaged effectiveness at two Tu-intensities

\section{Variation of the mainstream Mach number}

Experiments were carried out at Mach numbers of 0.3 and 0.5 and blowing ratios of 0.3 and 0.7 , at two turbulence intensities. In Fig. 10 is shown that from about 20 hole diameters downstream of injection the effectiveness is unaffected by the Mach number, which was also found by Liess (1975). In the near hole region however, the higher Mach number tests yield slightly higher values. However, this difference can be probably attributed to the changing boundary layer thicknesses, which decreases with increasing Mach number. Other researcher have also found that with increasing $\delta_{1} / \mathrm{d}$ the effectiveness decreased (Liess, 1975, Pederson et al., 1977, Foster and Lampard, 1980).

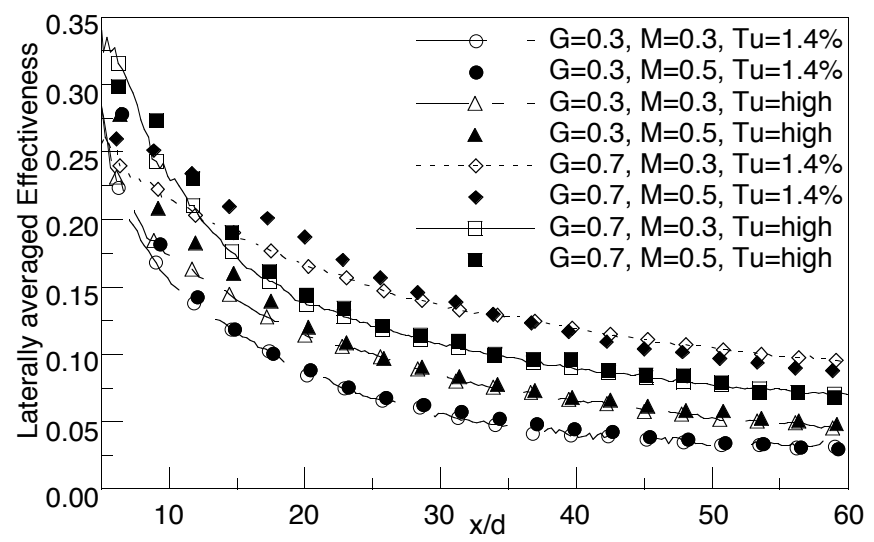

Fig. 10 Laterally averaged effectiveness at two Mach numbers

\section{Comparison of effectiveness to literature results}

Comparisons of centerline effectiveness results, $\eta_{c}$, were made to data by Sinha et al. (1991) and Schmidt et al. (1994), who used injection geometries similar to the present study. For both low and high blowing ratios the agreement between the results is good (Fig. 11), although the data of the present study shows a decrease of effectiveness at a slightly greater rate.
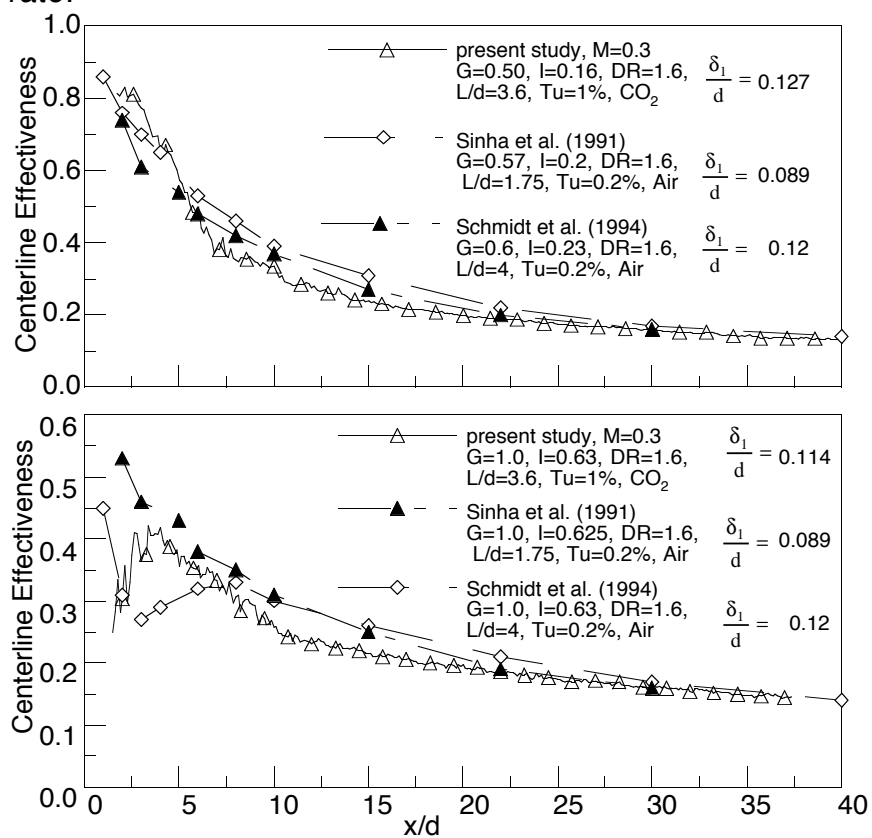

Fig. 11 Centerline effectiveness comparison with published data

The differences can be attributed to differences in freestream turbulence intensity and boundary layer thickness, which were higher in the present study. As pointed out earlier, both of these factors tend to reduce the effectiveness and thus explain the observed deviations. 


\section{FILM COOLING HEAT TRANSFER COEFFICIENT Effect of blowing/momentum flux ratios}

Laterally averaged heat transfer augmentation with respect to an uncooled baseline test without cooling holes is presented in Fig. 12, for different blowing ratios at $M=0.3$ and $\mathrm{Tu}=1.4 \%$. For all except the highest blowing ratio a remarkable increase in heat transfer is limited to about 10 hole diameters downstream of injection, whereafter it decreases to a value of 1. Only for the highest blowing ratio, a maximum of $20 \%$ increase occurs at $x / d=20$, which indicates the reattachment location of the jets after lift-off behind injection.

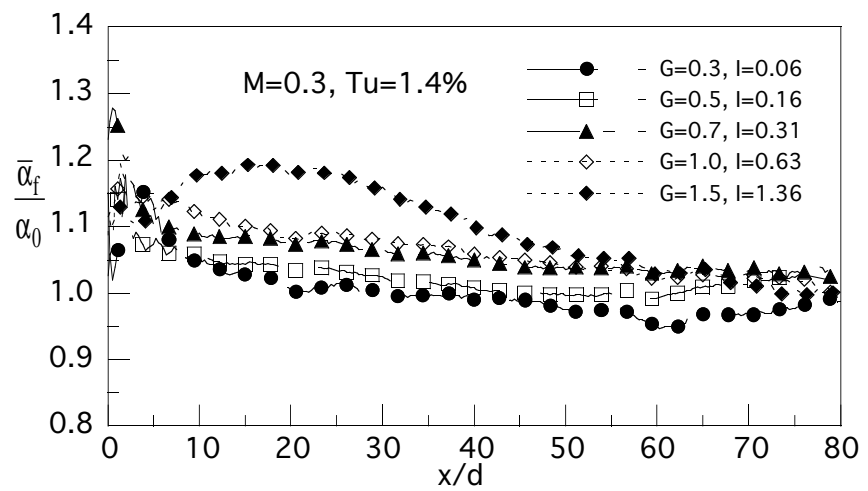

Fig. 12 Laterally averaged heat transfer augmentation

The spanwise distribution of heat transfer for $G=0.5$ is depicted in Fig. 13. The heat transfer is increased at locations where the edge of the jet and the mainstream interact. Such behavior was observed for all blowing ratios. Results from Eriksen and Goldstein (1974) showed the same trends.

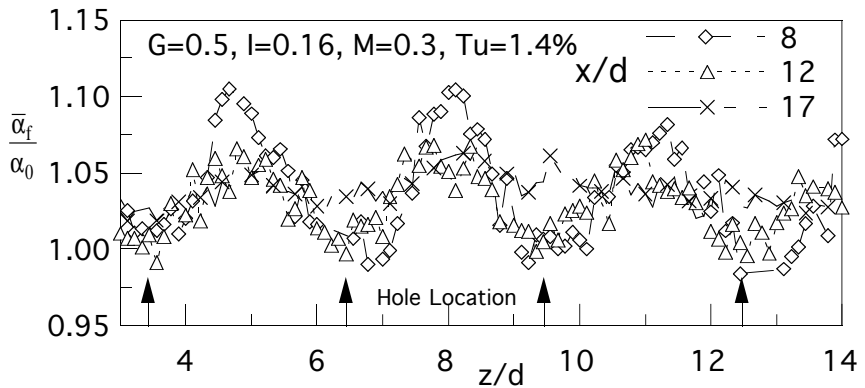

Fig. 13 Spanwise heat transfer augmentation

\section{Comparison of heat transfer to literature results}

Comparisons of laterally averaged heat transfer were done with data published by Ammari et al. (1990) who conducted film cooling heat transfer measurements at two density ratios of 1 and 1.52 .

For a blowing ratio of 0.5 , the present data agrees well with that by Ammari et al. (1990), whereas the rate of decrease is significantly lower at a blowing ratio of 1 (Fig. 14). This may be due to different boundary layer thicknesses and conditions. Lateral distributions shown by Ammari et al. indicated maximum heat transfer in the hole centerlines, whereas in the present study highest heat transfer was observed in-between the holes.
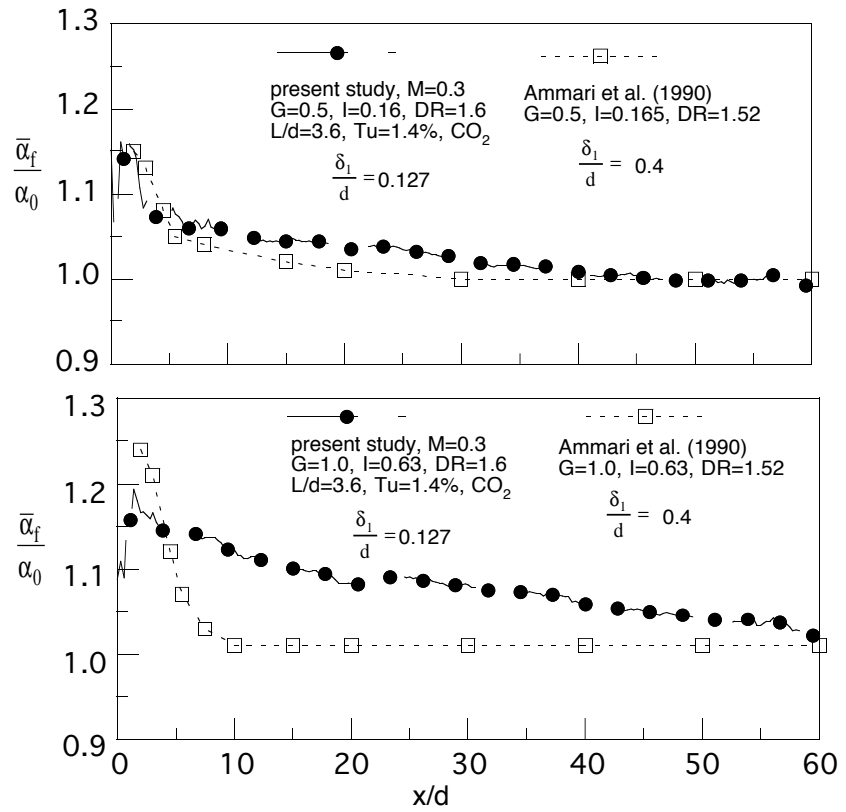

Fig. 14 Laterally averaged heat transfer augmentation comparison with Ammari et al. (1990)

\section{TURBINE AIRFOIL}

\section{Test Facility}

The measurements on the turbine airfoil were performed in a linear turbine cascade facility with five airfoils mounted onto a cylindrical disc in the $99 \times 340 \mathrm{~mm}$ working section as shown in Fig. 15. An insertion mechanism was employed for the transient tests where a pneumatic cylinder pulls the airfoil very rapidly (below $0.1 \mathrm{~s}$ ) through the sidewalls of the linear cascade, which has been described in Hoffs et al. (1996). For the present measurements, a new insertion system was constructed to allow film cooling on a modern airfoil geometry with a contoured endwall (Hoffs, 1996). A large cooling system was installed to pre-condition the initial and the film coolant temperatures below zero degrees Celsius.

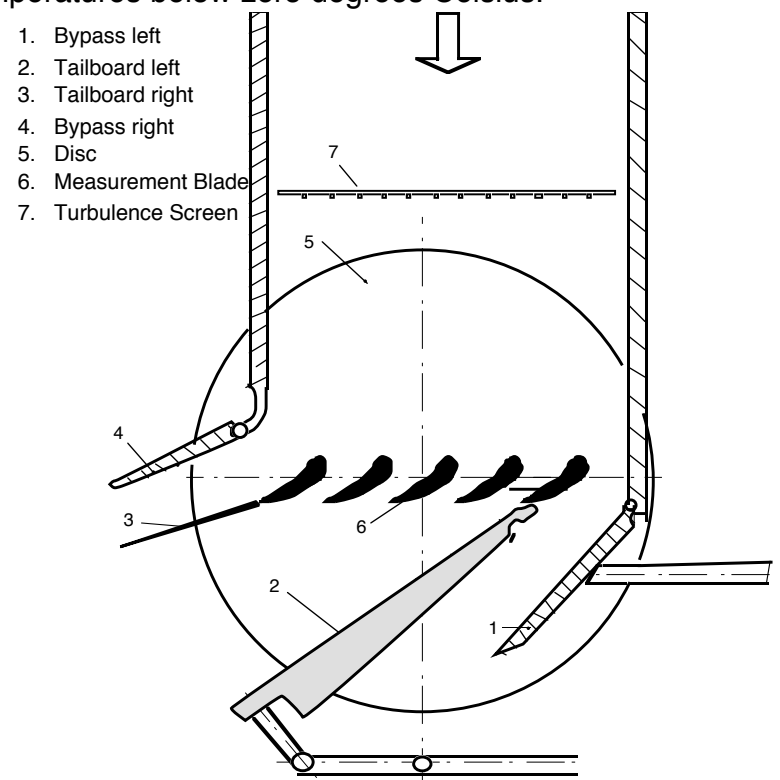

Fig. 15 Schematic view of the linear test facility 
One film cooling row was placed respectively on the pressure and the suction side close to the leading edge. Additional measurements were performed on the suction side with a double-row configuration. The dimensionless positions of the film cooling holes with respect to the geometrical leading edge are $s / L_{P S}=-0.123$ for the pressure side row and $\mathrm{s} / \mathrm{L}_{\mathrm{SS}}=0.377$ for the suction side rows (Table 2 ). The coolant was supplied from one side to a cylindrical plenum chamber in the blade, and the film holes were sharp entry.

\begin{tabular}{cccccc} 
Geometry & $\mathrm{s} / \mathrm{L}$ & $\varphi\left[^{\circ}\right]$ & $\gamma\left[^{\circ}\right]$ & $\mathrm{p} / \mathrm{d}$ & $\mathrm{I}_{\mathrm{h}} / \mathrm{d}$ \\
\hline single PS & -0.123 & 55 & 60 & 6.25 & 9.25 \\
single SS & 0.377 & 35 & 90 & 3.75 & 11.0 \\
double SS & 0.377 & 30 & 90 & 4.30 & 11.0
\end{tabular}

Table 2 Film cooling configuration airfoil

\section{RESULTS AND DISCUSSION AIRFOIL}

The measurements on the airfoil were performed at enginerepresentative exit Reynolds and Mach numbers of $1.5 \mathrm{e} 6$ and 0.8 . A high turbulence intensity of $10 \%$ with a lengthscale of $13 \mathrm{~mm}$ at the leading edge was achieved with a grid located 10 mesh sizes upstream of the leading edge. The blowing and momentum flux ratios were 4 and 9 for the pressure side, 1 and 0.5 for the suctions side single row, and 0.78 and 0.38 for the suction side double row (Table 3).

\begin{tabular}{cccccc} 
Geometry & $\mathrm{M}_{2}$ & $\mathrm{Re}_{2}$ & $\mathrm{G}$ & $\mathrm{I}$ & $\mathrm{DR}$ \\
\hline single PS & 0.8 & $1.5 \mathrm{e} 6$ & 3.84 & 8.78 & 1.69 \\
single SS & 0.8 & $1.5 \mathrm{e} 6$ & 0.93 & 0.55 & 1.60 \\
double SS & 0.8 & $1.5 \mathrm{e} 6$ & 0.78 & 0.38 & 1.60
\end{tabular}

Table 3 Airfoil test conditions

In Fig. 16, the isentropic Mach number distribution is shown together with the baseline heat transfer measurements carried out without holes, which were measured at midspan. Along the suction side, there is an initially strong acceleration of the flow up to $\mathrm{s} / \mathrm{L}=0.45$, whereafter it becomes almost uniform. Transition is observed between 0.5 and 0.8 with a turbulent boundary layer close to the trailing edge. On the pressure side the acceleration is almost constant. The heat transfer measurements indicate a laminar boundary layer which becomes transitional near the trailing edge.

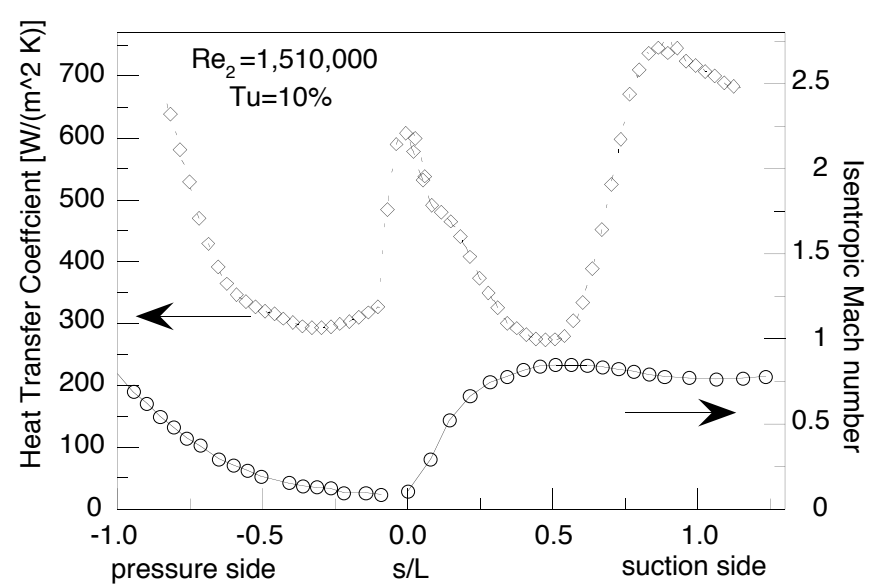

Fig. 16 Airfoil Mach number distribution and heat transfer without injection

Film cooling effectiveness results on the airfoil are shown in Fig. 17. On the suction side, a value of 0.3 is observed behind the holes with slightly higher values for the double-row configuration which is due to a better film coverage and a higher mass flow rate. For this configuration, measurements were also taken at the leading edge, and the evaluation shows the expected zero effectiveness. The effectiveness on the pressure side is very low with a short peak behind the holes, and a constant value of 0.05 further downstream.

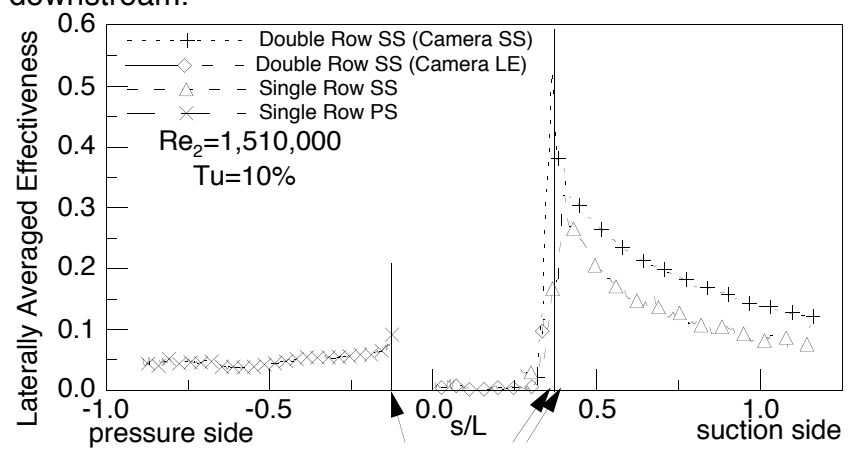

Fig. 17 Film cooling effectiveness on the vane

Film cooling heat transfer augmentation is shown in Fig. 18. On the suction side laminar-turbulent transition is triggered at the injection location for both the single- and double-row configuration, resulting in a tremendous heat transfer augmentation of up to 3.5. Stronger mixing in the double row case gives values above those for the single row, especially in vicinity of the holes. Towards the trailing edge, where the boundary layer of the baseline tests is equally turbulent, no heat transfer augmentation is observed. On the pressure side, the boundary layer relaminarized downstream of injection, and transition occurs then towards the trailing edge, very similar to the baseline. A moderate heat transfer augmentation of 1.4 occurs at the pressure side injection location, but decreases rapidly to a value of 1 further downstream.

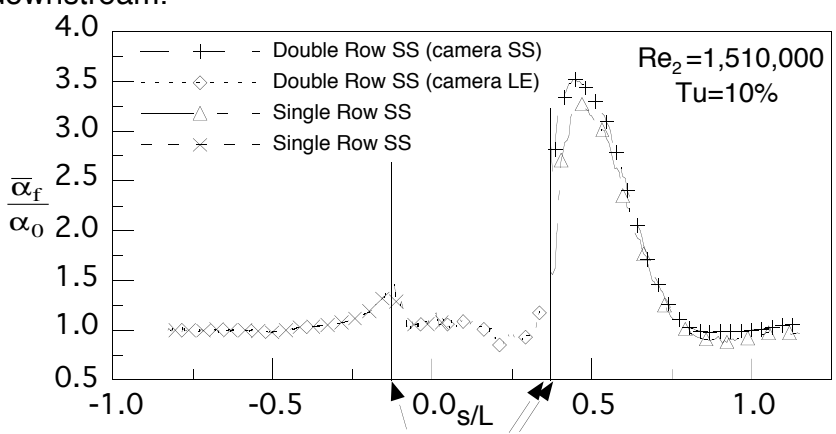

Fig. 18 Film Cooling heat transfer augmentation

\section{Conclusions}

- The transient liquid crystal technique has been successfully used for film cooling measurements on a flat plate and a turbine airfoil. A multiple-test regression method has been developed for the data reduction, considering a transient coolant temperature evolution.

- Flat plate film cooling effectiveness results compared well with published data for all momentum flux ratios, at low turbulence intensities. Heat transfer results were in good agreement for low momentum flux ratios, but showed increased values at higher coolant momentum. 
- Mainstream turbulence reduces flat plate effectiveness at low and moderate blowing ratios, but increases the effectiveness at high blowing ratios due to a better dispersion of the detaching jets in the boundary layer.

- Film cooling measurements on a gas turbine airfoil at engine-representative conditions revealed a maximum effectiveness of 0.3 on the suction side with slightly higher values for the double row, but only low effectiveness on the pressure side. On the suction side, transition was initiated at the injection location.

\section{ACKNOWLEDGMENTS}

The research project is subsidized by $A B B$, Baden, Switzerland and the "Nationaler Energie-Forschungs Fonds" (NEFF), Switzerland. The authors are very grateful to Dr. B. Weigand for his revision of the paper.

\section{REFERENCES}

Ammari , H.D., Hay, N., Lampard, D., 1990

The Effect of Density Ratio on the Heat Transfer Coefficient from a FilmCooled Flat Plate.

ASME Transactions, Vol. 112, pp. 444-450

Baines, W.D., Peterson, E.G., 1951

An Investigation of Flow through Screens.

ASME Transactions, Vol. 73, pp. 467-480

Bajura, R.A., 1971

A Model for Flow Distribution in Manifolds

Journal of Engineering for Power, January 1971

Bendat, J.S., Piersol, A.G., 1986

Random Data, Analysis and Measurement Procedures

John Wiley \& Sons 1986

von Doenhoff, A.E., Horton, E.A., 1956

A Low-Speed Experimental Investigation of the Effect of a Sandpaper Type of Roughness on Boundary Layer Transition

NACA Technical Note 3858

Eriksen, V.L., Goldstein, R.J., 1974

Heat Transfer and Film Cooling Following Injection Through Inclined

Circular Tubes

Journal of Heat Transfer, May 1974, pp. 239-245

Forth, C.J.P, Loftus, P.J., Jones, T.V., 1985

The Effect of Density Ratio on the Film Cooling of a Flat Plate

AGARD CP 390, Bergen

Foster, N.W., Lampard, D., 1980

The Flow and Film Cooling Effectiveness Following Injection through a Row of Holes

Journal of Engineering for Power, July 1980, Vol. 102, pp. 584-588

Häring, M., Hoffs, A., Bölcs, A., 1995

An Experimental Study to Compare the Naphthalene with the Liquid Crystal Technique in Compressible Flow

ASME Paper 95-GT-16

Hoffs, A., Drost, U., Bölcs, A., 1996

Heat Transfer Measurements on a Turbine Airfoil at Various Reynolds Numbers and Turbulence Intensities Including Effects of Surface Roughness

ASME Paper 96-GT-169

Hoffs, A. 1996

Experimental Investigations of Heat Transfer and Film Cooling Effectiveness using the Transient Liquid Crystal Technique

Ph.D. Thesis, Swiss Federal Institute of Technology-Lausanne (EPFL)

Kline, S.J., McClintock, F.A., 1953

Describing Uncertainties in Single Sample Experiments

Mechanical Engineering, January 1953

Liess, C., 1975

Experimental Investigation of Film Cooling with Ejection from a Row of Holes for the Application to Gas Turbine Blades

Journal of Engineering for Power, Transaction of the ASME, January 1975

Ligrani, P.M., Camci, C., 1985

Adiabatic Film Cooling Effectiveness from Heat Transfer Measurements in Compressible, Variable-Property Flow

Journal of Heat Transfer, Vol.107, pp. 313-320

Schlichting, H., 1968

Boundary Layer Theory

6th ed., McGraw-Hill, New York

Schmidt, D.L., Bogard, D.G., 1996

Effects of Free-Stream Turbulence and Surface Roughness on Film Cooling
ASME Paper 96-GT-462

Schmidt, D.L., Sen, B., Bogard,D.G., 1994

Film Cooling with Compound Angle Holes: Adiabatic Effectiveness

ASME Paper 94-GT-312

Sinha, A.K., Bogard, D.G., Crawford, M.E., 1990

Film Cooling Effectiveness Downstream of a Single Row of Holes with Variable Density Ratio

ASME Paper 90-GT-43

Teekaram, A.J.H., Forth, C.J.P., Jones, T.V., 1989

The Use of Foreign Gas to Simulate the Effects of Density Ratios in Film Cooling

Journal of Turbomachinery, January 1989, Vol. 111, pp. 57-62

Teekaram, A.J.H., Forth, C.J.P., Jones, T.V., 1990

Film Cooling in the Presence of Mainstream Pressure Gradients

ASME Paper 90-GT-334

Vedula, R.,J., Metzger, D.E., 1991

A Method for the Simultanenous Determination of Local Effectiveness and Heat Transfer Distributions in Three-Temperature Convection Situations

ASME Paper 1991

Wang, Z., Ireland, P.T., Jones, T.V., 1994

A Colour Image Processing System for Transient Liquid Crystal Heat Transfer Experiments

ASME Paper 94-GT-290 